\title{
Reseña del libro La democracia a través de los derechos: el constitucionalismo garantista como modelo teórico y como proyecto político de Luigi Ferrajoli (2014)*
}

\author{
Andrea España Carreño \\ Universidad de Medellín, Medellín, Colombia \\ andreaespana767@gmail.com
}

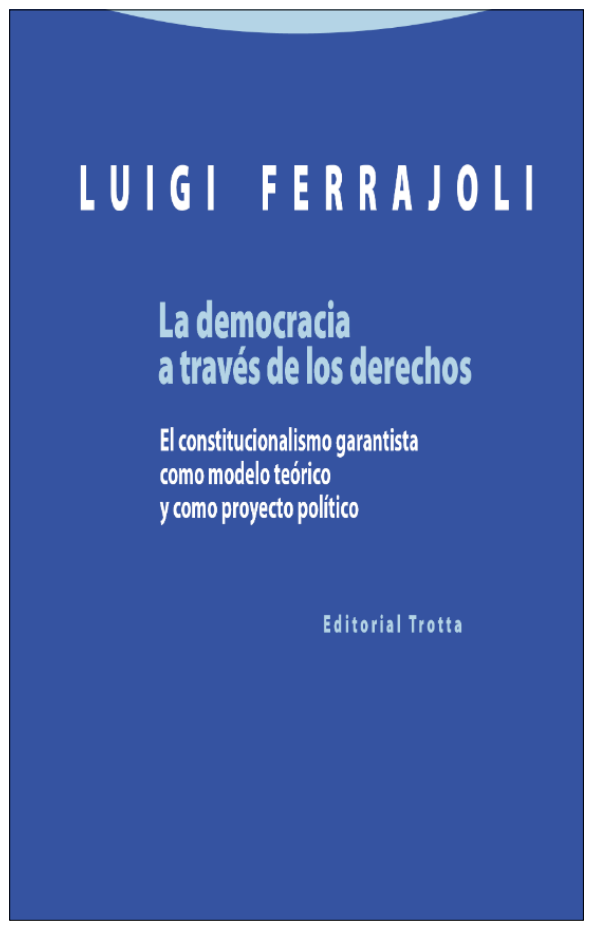

Cubierta del libro La democracia a través de los derechos

Fuente: Ferrojali (2014).

Cómo citar: España, A. (2020). Reseña del libro La democracia a través de los derechos: el constitucionalismo garantista como modelo teórico y como proyecto político de Luigi Ferrajoli (2014). Ciencias Sociales y Educación, 9(17), 373-378. https://doi.org/10.22395/csye.v9n17a20

Recibido: 7 de noviembre de 2019.

Aprobado: 18 de febrero de 2020. 
El libro La democracia a través de los derechos del jurista italiano Luigi Ferrajoli explica la relación directa que existe entre la democracia y la garantía de los derechos fundamentales. La democracia expresa la voluntad popular de una sociedad y un método a través del cual se toman decisiones importantes para la solución de problemas que atentan con las emociones y los pensamientos de todos los asociados. El libro es un ejercicio académico que analiza la manera como se lleva a cabo la democracia en el contexto latinoamericano y, en ese orden de ideas, muestra de qué manera los Estados dejan de lado el nexo conceptual que existe entre derechos y democracia. La tesis central reposa en describir la democracia como un hilo conductor a través del cual se asegura la fijación de garantías y de pautas, casi siempre eficientes, que aseguren la mayor esfera de realización de los derechos fundamentales. Afirma Ferrajoli (2014) que la salvaguarda de los derechos fundamentales en general, y los sociales en particular, exige una sobreposición de la política sobre la economía.

El desarrollo de estas ideas se teje a través de dos capítulos que componen el texto. En el primer capítulo, en el que se describe la estructura teórica del modelo democrático constitucional, encontramos respuesta a tres grandes preguntas: (i) ¿cuál es el soporte teórico desde el cual se explica la relación entre democracia y derechos?; (ii) ¿qué entender por el término constitucionalismo garantista?; y (iii) ¿cómo explicar la naturaleza del constitucionalismo a partir de principios? En el segundo capítulo, donde se desarrolla el alcance político del modelo, se responden dos preguntas (i) ¿cómo evidenciar la crisis de la democracia constitucional?; y (ii) ¿cómo puede concebirse el futuro de la democracia constitucional? La respuesta a cada una de estas preguntas nos permitirá poner en evidencia las tensiones que se derivan de la inmodificable exigencia de concebir la democracia como el escenario idóneo, posible y necesario en el que la realización de la más amplia esfera de derechos, individuales y sociales, puede tener lugar.

El modelo teórico trajo consigo un cambio sustancial en la concepción que se tenía sobre las condiciones de validez de las leyes; no solo en términos procedimentales, sino en sentido material. Esto quiere decir que se ha de aceptar como válida solo aquella norma que, además de asegurar las exigencias formales, se haga correspondiente con los preceptos constitucionales (principios, valores y derechos fundamentales).

La democracia constitucional se define bajo tres postulados: (i) derecho jurisprudencial, el cual consiste principalmente en un patrimonio de máximas categorías, principios y precedentes judiciales transmitidos por la cultura y la práctica jurisprudencial. Su cumplimiento depende de su contenido y sustancia prescriptiva; vigila la validez y legitimidad de la norma. (ii) Derecho 
legislativo: se establece con el propósito de conocer con exactitud el principio de legalidad, puesto que las normas se reconocen por su producción y no por su contenido. (iii) Derecho constitucional: establece un cambio. Dispone una nueva organización de los derechos y busca que el Estado garantice su cumplimiento; identifica la coherencia entre la norma y su contenido. Estos tres postulados tienen un propósito común vigilar y garantizar el cumplimiento de los derechos fundamentales del individuo.

El constitucionalismo garantista establece las condiciones de validez de las leyes y el cambio en la estructura del Estado de derecho. Define cuatro postulados. (i) Principio de la legalidad: su función es garantizar que donde exista un poder público, privado, ejecutivo o judicial, haya normas y leyes que regulen su ejercicio para evitar confusiones en la concentración de asuntos que son de su competencia directa; (ii) principio de plenitud deóntica: busca establecer normas que estén directamente relacionadas con las garantías y el cumplimiento de los derechos establecidos en la Declaración Universal de los Derechos Humanos; (iii) principio jurisdiccional: promueve la imposición de normas secundarias en caso de incumplir las normas primarias, por lo que los jueces no solo están sujetos a la ley, sino a que su actuar esté fundado en los principios constitucionales que subyacen a éstas; y (iv) principio de accionalidad: asume el total cumplimiento de los tres principios mencionados anteriormente ejercido por un órgano público legalmente constituido. Los principios (i) y (ii) expresan una relación de carácter normativo y lógico del constitucionalismo; y los principios (iii) y (iv), de estricto cuño garantista, expresan su preocupación por el correcto cumplimiento de lo establecido por el constitucionalismo. Estos principios, en conjunto, diseñan el marco general de reglas que disciplinan la producción del derecho y aseguran así la plena legitimidad de su contenido.

El constitucionalismo principialista concibe las normas constitucionales como principios idóneos para articular el derecho y la moral a través de la argumentación. Los derechos fundamentales y en general los principios contenidos en la constitución contienen evidentes valores morales y políticos de justicia, motivo por el cual muchos constitucionalistas consideran que su constitucionalización ha hecho insostenible el principio positivista de la separación entre el derecho y la moral. Teniendo clara la diferencia entre derecho y moral, el derecho es de carácter positivo respecto de la norma, y la moral no está sujeta solo al rango constitucional. La ponderación, en una clara diferencia metodológica con la propuesta de Robert Alexy, no es la solución de los problemas interpretativos debido a que los principios no son normas expuestas a las opciones deliberadas del legislador o de los jueces, sino que son verdaderos límites y vínculos impuestos a uno y a otros. 
La separación de poderes resulta comprometida por las doctrinas principialistas porque concibe los derechos constitucionalmente establecidos como principios de ponderación y no como reglas objeto de aplicación. Los derechos fundamentales, que solo tienen lugar en un régimen democrático, comprometen la aplicación de la ley y la exclusiva subordinación a la misma.

El paradigma constitucional es un modelo imperfecto debido a la divergencia deóntica que siempre existe entre normatividad y efectividad; entre más ambiciosas sean las promesas constitucionales más amplia es la divergencia, por eso se debe hablar de mayor o menor grado de garantismo. Solo en los Estados absolutistas existe coincidencia entre existencia y validez de las normas producidas por el ejercicio del poder público. Este riesgo de la democracia constitucional de estar a punto de entrar en crisis es de ruptura, debido a dos fenómenos: (i) el desarrollo de la ilegalidad y (ii) el defecto de la legalidad. El primero de ellos, en el ejercicio de los poderes públicos normativos, se manifiesta en las violaciones de garantías y con ello la producción de antinomias. El segundo efecto se expresa en la existencia de vacíos normativos.

Las razones de la crisis son múltiples. Se señalan algunas: la falta de introducción de garantías a la altura de los nuevos poderes; el hecho de que la política no ha aceptado su sujeción al derecho; la pérdida de memoria de las tragedias del pasado; la reducción del papel del gobierno y de garantías de la esfera pública. Pero, señala el autor, el principal factor es la crisis económica, dada la abierta subordinación de la política a la economía. Estas dos variaciones consisten en la asimetría existente entre política y economía. El poder económico dispone de un radio de acción global; a diferencia del poder local que contiene la esfera jurídica o política. Sumado a lo anterior, es importante señalar el efecto cultural de la instalación cotidiana del ideario neoliberal. A partir de dicho ideario, se adoptan postulados racionales acerca de la concepción de los poderes económicos donde las libertades fundamentales se amalgaman con las leyes de mercado y las leyes naturales.

Existe una creciente confusión entre poderes políticos y poderes económicos que se manifiesta en las múltiples formas de corrupción, en los variados conflictos de intereses y en la relación cada vez más estrecha entre política y economía. El cambio en la estructura económica de los países, derivado de tratados y pactos internacionales, impide al Estado asegurar las disposiciones constitucionales. Esta relación entre política y economía está produciendo una profunda crisis institucional que afecta tanto a la dimensión formal como a la sustancial de nuestras democracias. Afecta las formas de la democracia política, que nació dentro de los Estados con el sufragio universal, en la elección de los representantes de los supremos órganos estatales y ha 
estado siempre vinculada a las formas representativas de parlamentos y de gobiernos nacionales.

La actual crisis de la democracia en todas sus formas y sus dimensiones encarna la incapacidad de la política frente a desafíos globales, es así que el constitucionalismo garantista, gracias a la normativa asociada a la mayor parte de los principios constitucionales, se revela no solo como un modelo teórico, sino como un proyecto político en construcción de la democracia. En este sentido, la tesis de Ferrajoli no es mostrar la vocación redentora de la democracia, lo cual tipificaría un lugar común, sino demostrar este nexo causal entre democracia y derechos fundamentales por cuanto la crisis de la democracia, contenida en ilegitimidad y poca representación ciudadana, representa y significa un desmedro institucional, social y cultural de la necesaria apuesta estatal por asegurar la integridad y realización de los derechos fundamentales.

Las dificultades que se oponen a la perspectiva de un constitucionalismo global no son de carácter teórico, sino de carácter político. Política, derecho y economía ya no podrán ser como antes, deberán poner fin a la inversión de sus relaciones que dan origen a la crisis del constitucionalismo. La expansión en sentido extensional del paradigma constitucional consiste en su ampliación a la altura de todos los poderes, públicos y privados, desarrollados fuera de la esfera de los poderes estatales, y a su vez, en el reforzamiento del mismo paradigma en sentido intencional. Esto requiere la refundación de la dimensión formal de la democracia representativa a través de la rehabilitación de la política y la reestructuración de la esfera pública sobre la base de un sistema complejo de separación de poderes en garantía de los derechos políticos y civiles, que va más allá de lo establecido en el contrato social.

El paradigma constitucional reclama innovación política, invención jurídica y separación efectiva de poderes, tanto a nivel orgánico como adentro del poder estatal. Reclama separación del poder político y jurídico de la esfera economicista. Deben liberarse a los partidos políticos de favores económicos. A los partidos políticos, dinamizadores de la democracia, debe impulsarlos la ideología, el debate, el foro público, el control político y la iniciativa legislativa; y solo en tanto aseguren dicha independencia, podrán ocuparse de tejer el puente necesario con la sociedad: a la que se deben y de la que nacen. Alejar a los partidos políticos de la dependencia exclusivamente económica significa oxigenar la democracia, reducir la corrupción y dirigir la política a la búsqueda del bien común. En ese buen direccionamiento del poder público, los derechos fundamentales ya no serán concebidos como bienes sujetos a las leyes del mercado, sino como atributos individuales e indivisibles que condicionan la salud del régimen y la legitimidad de un modelo teórico y práctico capaz de 
rehabilitar el papel de la política y de la creación legislativa; capaz de acompañar el renacimiento del compromiso ciudadano, incentivado por la representación de movimientos sociales en la esfera pública (institucional) de la política.

\section{Referencias}

Ferrajoli, L. (2004). La democracia a través de los derechos: el constitucionalismo garantista como modelo teórico y como proyecto político (trad. Perfecto Andrés Ibáñez). Editorial Trotta. 